\title{
The Development of Centralized Processing For School Libraries During The 1960's: A Literature Survey
}

\author{
by Carolyn Lucille Shelhorse \\ Danville, Virginia
}

\section{General Characteristics of Central}

Processing Units and Recent Trends in Their Development

Centralized processing is generally defined as the use of one physical facility to accomplish the ordering, cataloging, and physical preparation of materials for a number of individual libraries. During the 1960's, centralized processing became a national library trend for all types of systems. Many school library administrators introduced it to their districts with the same hopeful expectation as did public and academic librarians. It was assumed that this new organizational pattern would provide the solutions to several plaguing problems.

First and perhaps most important was the problem of the rising cost of processing. It was reasoned that centralized processing would eliminate the duplication of effort then being made by highly paid professional librarians to catalog and process the same titles. At a processing center original cataloging could be done once and the routine work of copying could be performed by clerical help.' It was also argued that expensive reference tools and equipment would have to be purchased only once if processing centers were established. Finally, it was believed that better discounts could be secured from book jobbers if orders were pooled. ${ }^{2}$

A second problem facing library administrators during the 1960 's was the shortage of qualified librarians. In many states, persons with only limited training were stationed in school libraries. Often teachers were used, while in other cases unqualified persons, were employed because the certification requirements were low. Centralized processing was advocated in these systems since it would relieve the librarians who were weak in cataloging from this responsibility. ${ }^{3}$ Also, numerous schools had no librarians at all, and it was maintained that centralized processing would provide their collections with accur- 
ately and consistently cataloged materials without depending on volunteer parent or teacher aid. ${ }^{4}$

A third problem was the increase in materials to be processed. During the 1960 's, federal funds were widely distributed for the purchase of library resources. Central processing was advocated as a way to prevent backlogs of these newly acquired, unprocessed materials.

Several positive advantages of centralized processing were emphasized. Individual school librarians would have more time to help both students and faculty use the library if the processing responsibility were removed from them. ${ }^{5}$ Secondly, whole collections could be made ready for use by opening day in the numerous schools being established in urban areas. ${ }^{\circ}$

Actually however, centralized processing was not a new idea in the 1960's. Indeed, the Mahar and Holladay study for the United States Office of Education entitled Statistics of Public School Libraries reported that in 1961 at least 467 school systems were providing centralized processing for their elementary schools, while 239 secondary libraries were receiving the service. The largest percentage of these systems were located in either the far west or the Great Lakes regions.'

Despite the obvious awareness and use of centralized processing by schools prior to 1960, the emergence of a major trend occurred after that date. No doubt, many school systems were prompted to initiate processing centers by the encouragement given in several studies published early in the decade and by the following statement in the 1960 Standards for School Library Programs: "Centralized technical processing constitutes a form of cooperative planning for school libraries that takes place be- fore the establishment of a materials center. When school systems have three or more schools, centralized processing should be introduced." ${ }^{8}$ This early enthusiasm unfortunately was not always accompanied by careful reasoning and planning. Later authorities in the field argued that the 1960 Standards were wrong to encourage a system with only three schools to centralize its processing. By 1966, Richard Darling was suggesting that school systems should consider instituting processing centers only if they purchased as many as 45,000 to 50,000 volumes a year and if they were expanding and adding entire new schools and library collections. ${ }^{\circ}$ Nevertheless hundreds of processing centers were established during the 1960's.

Keep up-to-date with the everchanging periodicals world.

\section{Binding Reference Serials Records}

They all need Faxon's

\section{Serials Updating Service Quarterly}

a quarterly newsletter containing the most current information on various serials titles. All changes (title, frequency, etc.) and bibliographic irregularities (additional volumes, delays in publication, etc.) are reported as Faxon is make aware of them. Each issue contains an average of 650 entries. A full-year subscription costs only $\$ 7.00$; two-years $\$ 13.50$; threeyears $\$ 20.00$. Throughout the year. special issues containing additional information that Faxon feels will be of value to librarians will be offered to subscribers at no additional cost. A special Membership Issue is planned for 1975. Sample copies on request.

\section{[EWF. F.W. FaXon CompanY,InC.}

Publishing Division

15 Southwest Park, Westwood, Mass. 02090

Southern Office: P.O. Box 1000, Marietta, GA 30061, Tel: (404) 971-1323 
During the early stages, most school processing centers were organized within and administered by a single school district. While it is true that in some states school libraries received processing services from public libraries and area processing centers, this was far from the predominant pattern. $^{10}$ The single district centers generally initiated their services on a limited basis. A problem was identified, the center was established to solve it, and after the resolution of the problem, the processing center's program was expanded to meet less pressing needs. In most cases, processing was offered to elementary schools first. Their need was greatest because many new elementary schools were being built requiring complete new collections and elementary school libraries were generally staffed by fewer professional librarians than were secondary schools. A third reason for beginning processing with elementary schools was the fact that duplication of titles is greater among their collections."

The services offered by school processing centers varied widely from district to district. The ranges from partial to full services were great. Some centers performed only the ordering and cataloging functions, thus leaving the final physical processing to the individual librarian, while other systems supplied processed materials only to new schools or to special collections. $^{12}$ Many centers provided processing for book materials only, while others included the handling of all types of audiovisual materials. Most centers purchased commercially printed cards, but varying uses were made of them. Some systems bought printed cards only for small special collections, while other centers purchased all the cards which were available.
Some centers used printed cards entirely, purchasing a set for each volume processed, while other systems bought only one set and reproduced copies at the processing center. ${ }^{13}$

Staff size and duties were generally comparable from district to district. The United States Office of Education's study previously cited reported that in 1961, 370 professional and 707 clerical workers were employed in the nation's school processing center. ${ }^{14}$ Two primary professional positions were identified. First was the administrator of centralized processing who was responsible for the management of processing as well as the supervision of the catalogers and clerical workers. This position was generally subordinate to the head supervisor or director of library services. The second professional position was that of cataloger which carried the usual responsibilities. The average school processing center employed from 2 to 5 professional persons and from 3 to 10 clerical workers. ${ }^{15}$

The physical quarters provided for central processing units were often barely adequate during the 1960's. Many centers were set up in leftover storage buildings, in basements or annexes to the systemwide administration building, and in old school buildings no longer used for instruction. Even when remodeling was attempted, many of these structures could not be altered to allow for a smooth workflow arrangement of the furnishings.

The processing centers of the 1960's depended on various types of equipment to facilitate their production. Administrators reasoned that the cost of such machines was more than offset by the speed they introduced into the process and by the professional appearance they gave to the end product. Therefore, many centers 
invested in an assortment of pasting machines, call-number lettering machines, and duplicating equipment. ${ }^{16}$ In Viola James' 1963 study of nineteen major school processing units, a wide variety of different duplicating machines were found to be in use. Three systems were utilizing the small hand-operated Cardmaster roller-applicators. The most commonly used duplicating methods, however, were mimeograph or stencil duplication and offset duplication. It was noted by the author that several of the systems which were employing offset processes for duplication were producing less than the 85,000 cards a year which the American Library Association's Library Technology Report has indicated is the least number possible for such equipment to function economically. ${ }^{17}$ In the latter half of the decade, many centers switched to direct copy Xerox equipment. At least two school systems invested in data processing equipment and fully computerized their processing.

Because central processing was introduced in many school systems at least partially for the purpose of reducing the cost of preparing materials for use, administrators have been very interested in determining whether their processing units have, in fact, performed economically. Admittedly, few centers were able to show a savings in the first years of operation, because the initial cost of establishing processing units was so high. ${ }^{18}$ However, even after several years of production, cost figures varied widely from center to center. In James' survey, the estimates of the cost of production per book ranged from a low of $\$ 0.55$ to a high of $\$ 2.50$ to $\$ 3.00$. Most of the processing centers reported figures corresponding to neither of these extremes, however, with the cost averaging between $\$ 1.00$ and $\$ 1.50$ per item. The James study surprisingly did not indicate any pattern to the cost variations. Contrary to the predictions, costs did not necessarily go down as the number of items processed increased. Such inconsistencies may have been caused by poor record keeping, poor management policies, or simply the fact that costs are drastically changed by such disparate and uncontrollable factors as raises in clerical salaries, the purchase of new equipment, and the amount of duplication present within any particular year's production. ${ }^{19}$ Unfortunately, no adequate cost comparisons have been made recently between school processing center production and com-

\section{Associated Libraries, Inc.}

\section{CHILDREN'S CLASS A PREBOUND BOOKS}

Our catalog cards and processing service saves time. Our cards and kits arrive with books.

\section{A-V MATERIALS}

Send for our free catalogs. ASSOCIATED LIBRARIES, INC.

229 N. 63rd Street - Philadelphia, Pa. 19139 
parable commercial or individual school production.

During the latter half of the 1960's, two new trends in the organization and operation of school processing centers began to emerge. First was the trend toward regional processing centers. Many small school systems had found their processing centers to be uneconomical; therefore, administrators began to test the practicability of processing units which were to serve increasingly larger areas. Several organizational patterns were suggested for these new regional centers. Some favored the establishment of regional district centers which were to be administered either cooperatively by the participating schools or by the state in which the region was located. Others recommended a system in which one single center within the state was responsible for all cataloging while regional centers completed the rest of the physical processing. A third possibility considered was the establishment of a single center within each state to perform the entire processing function for all the schools under that state's jurisdiction. ${ }^{20}$

The second major trend identifiable at the end of the 1960's was toward the use of data processing equipment and computers for processing materials. Such equipment is capable of processing greater amounts of material in much less time than the conventional equipment employed largely because many of the routine procedures formerly done manually can be handled by the machine in a computer operation using punched cards with coded data. $^{21}$

\section{Individual Types Of Centers}

\section{Early Unmechanized Systems}

During the early 1960's, many small processing centers were established. These were largely unmechanized and their greatest advantage was that clerical workers rather than professional librarians performed the routine ordering, filing, typing, and pasting functions. The reports published on these centers often lacked detail; therefore, the researcher must compose the studies made of several such centers in order to produce an adequate picture of their operations.

The processing center for the Madison, Wisconsin, Public Schools was a typical one of this type. It served thirty-five schools. Book orders were submitted by individual school librarians to the center. These orders were coordinated at the center, and a set of Wilson cards was procured for each individual book. If Wilson cards were unavailable, original cataloging was done and sets were typed by the center's clerical staff. When both the books and the printed cards had been received, the remainder of the physical processing was completed. The Madison center also maintained a union file. One card was prepared for each title in the system. This card contained the basic bibliographic information for the title and coded symbols for all the schools in the system. Markings, which had been specially designed to indicate first, second, and third copies, were placed beside each school's symbol when the title was acquired. ${ }^{22}$

A 1961 study by Vincent Aceto of school processing centers in New York state indicated that procedures for those systems were quite similar to the ones used in the Madison unit. Of the twenty centers surveyed, eighteen purchased books with printed cards. Several centers indicated the additional purchase and processing of such items as periodicals, pamphlets, and audiovisual materials. Some centers provided the following non-processing services: the provision of bulletin board materials; the planning of book fairs; the preparation of book reviews, classified new book lists, and bibliographies; the supervision of interlibrary loans; and the coordination of school and public library services. ${ }^{23}$ The New York study also included information about the staffing and housing of the processing centers. Of the twenty centers studied, only one had a full-time professional librarian. Most of the others employed one of their regular librarians as the director of the processing 
center, thus, that person's time had to be split between service to an individual school and service to the processing center. All of the centers used clerical help. Over half employed at least two full-time clerks, while several systems used student volunteer assistants. The New York processing centers were generally located either in or adjacent to one of the school libraries or in the system's administration building. The physical facilities were usually considered inadequate. Need was expressed for additional work space, shelving, storage, and plumbing. ${ }^{24}$

In general, the early unmechanized processing centers seem to have been initiated without forethought and longrange planning. The physical facilities were makeshift, while the staffs were overburdened with too many responsibilities. By the end of the decade, many of these units had merged into district centers for greater efficiency.

\section{Early Mechanized Systems}

Not all of the processing centers of the early 1960's were as ill-planned as some of the small New York efforts. Many of the large urban city systems made detailed studies before initiating their processing centers and planned carefully for their eventual growth and expansion.

One such system was the Baltimore City Schools which began planning for its processing center as early as 1955. A study was first made of the system's existing curriculum topics, processing procedures and cataloging needs. Then centralized processing itself was studied through a thorough reading of articles on the subject, visiting of cataloging departments in the public and government libraries nearby, and compiling the results of a questionnaire. Finally, studies were read and tests made of the various techniques and equipment available. ${ }^{25}$

In the interest of orderly and smooth development, it was decided that Baltimore's processing center would be made operational in four stages. In 1956, actual card preparation began for the collections of eleven of the system's existing libraries as well as for one new junior-high school's basic collection. Six months later cataloging and processing services were extended to include all of Baltimore's secondary schools and seventeen additional juniorhigh schools. Five years after its opening, the Baltimore center was serving 132 out of the 188 schools in the city's system. ${ }^{20}$

The processing procedures adopted at the Baltimore center involved the mechanical duplication of cataloging done by the center's professional personnel rather than the purchase of printed cards. This method was chosen because the 1955 study had indicated that it was the most economical one available. Offset duplication equipment (Multilith \#80) was selected; however, mechanical problems were experienced with it. Because offset duplication is done from typed stencils, it was found necessary to purchase an electric typewriter along with a standard one for each staff member. Stencils were produced for popular titles and extra cards duplicated and stored until requested. For less popular titles, cards were typed individvally. Using these procedures and equipment, the processing center was able to produce 198,902 sets of cards within the first five years of operation. In addition, total processing was given to 166,373 books. During the month of September, 1960 , a peak production of 10,000 books was reached. ${ }^{27}$

In 1961, when the Baltimore processing center had reached full operation, its staff included one cataloger, one assistant cataloger who served as a liaison between the center and the individual schools, one typist, and two clerks. However, a definite need had been experienced for another cataloger, two more assistant catalogers, and two more clerks, one of which would work solely with the Multilith machine. It was noted that additional staff was particularly necessary during the summer months when processing reached its peak. $^{28}$

The Baltimore processing center was housed on the second floor of the central 
warehouse in a space containing 1,300 square feet. The structural remodeling given the building included the installation of flourescent lights, air conditioning, an asphalt tile floor, running water with sinks, and electrical outlets. Shelf space for 3,000 books was provided, and access to outside delivery areas was made easy. ${ }^{29}$

The administrators in Baltimore made careful cost studies during their first five years of operation. A comparison of these costs was made with the recorded production of the center, and it was estimated that in 1961 each book required an average of $52 \not \subset$ to process. ${ }^{30}$ By 1963, when Viola James' study was made, this figure had risen to $75 \not$. Despite the rise, the Baltimore center's cost were still considerably lower than the average. ${ }^{31}$

The success of this center and the many others like it confirmed the hypothesis that centralized processing could be an economically practical pattern of organization. The glowing reports issued were meant to assure the library world that centralized processing was not a passing fad, but a possible solution to some very plaguing problems. By the middle of the 1960's, librarians were no longer debating whether centralization of processing was a good idea; they were more interested in discussing hơ technological advances and organizational improvements could make the advantages even greater.

\section{Updated Mechanized Systems}

Although many single-district centers similar to the ones discussed above were established during the early and mid1960 's, in most cases reports of their activities and processes have not been undated since the initial introductory ones. It has been impossible, therefore, to document the changes and improvements which were made in these processing centers during the latter half of the decade. The Greensboro, North Carolina, City School processing center is one notable exception. In 1969, a study of its recent procedures and production was published. In order to supplement the information in the report with a final updating, the writer personally visited the facility in March, 1972.

By 1969, the Greensboro center was serving a total of forty-nine school libraries. Complete ordering, cataloging, and processing were being performed for both book and audiovisual materials. Throughout most of the decade, processing procedures remained unchanged. Commercially prepared catalog cards were ordered for each book being processed when available. All other cards were typed with the exception of cards for motion pictures which were mechanically reproduced. Stencils, made photographically from Library of Congress film cataloging, were used to reproduce these cards with offset duplicating equipment. Under this processing method, a total of 317,305 items were made ready for use from 1961 to $1968 .^{32}$ The cost of processing each item was estimated at $\$ 1.29$ in $1963 .^{33}$ In 1969, however, processing procedures and equipment were completely revised and changed. The purchase of commercially prepared cards and the typing of original cataloging were reduced to one set per title. These sets were then stored in a master file and copies duplicated upon request by individual school libraries. New duplicating equipment was procured. Following the example of many processing centers, a Xerox 914 direct-copy duplicating machine was rented. ${ }^{34}$

The number of staff members at the Greensboro processing center remained stable throughout the 1960's; however, duties were readjusted to correspond with the procedural changes instituted. In 1969, the center employed thirteen people, three of whom were professional librarians. The head cataloger served as the director of the processing center. Two actual catalogers were employed, one for book materials and one for audiovisual materials. Four duplicate cataloger-typists were used along with one filing clerk and one clerk for making Xerox copies. There were four processing assistants responsible for opening boxes, stamping, accessioning, 
pasting, jacketing, packing, and delivering materials. ${ }^{35}$

The Greensboro processing unit was located on the ground floor of the city school system's administrative building annex. The 4,900 square-foot room was divided into several work areas by strategically placed shelving which also served as book storage space. ${ }^{36}$

This processing unit was one of the most productive school centers in the state during the 1960's. Methods for improving its service were studied, and finally new procedures and equipment were installed in an attempt to meet the increased demand for processed materials.

\section{Regional And State Systems}

As mentioned earlier, a major trend during the second half of the decade was toward the establishment of regional and state processing centers. It was hoped that the added volume of work accomplished at these larger units would reduce the cost of processing for each individual item.

One such center was established by the Rhode Island Department of State Library Services. This center began its operations by offering processing services to eighteen school and public libraries. The output was later increased to include materials for 112 additional libraries. ${ }^{37}$

The processing procedures of the Rhode Island center were partially computerized. When orders were received from individual libraries, they were key-punched onto computer cards. The center's equipment was then used to sort the orders by book dealer and print out order sheets as well as bills. After the arrival of the books at the center, catalog cards were retrieved from the master process file or typed if the title were new to the center. Copies of these cards were reproduced photographically and sent with the processed items to the requesting library. Each library using the center's service was assigned a coded number which specified its distinct library type. School libraries were numbered in the 9000 's. This assigned number accompanied the book orders and was used by the processing center to determine the specific alterations which would be made in the master catalog cards. For school libraries, shorter classification numbers and simplified, shortened subject headings were superimposed on the master cards during the photographic process. $^{38}$

Unfortunately, the operation of the Rhode Island center did not prove to be an economical one. Although the center charged its customers a reasonable $\$ 1.00$ per volume for the service, the actual cost of processing was estimated to average $\$ 2.22$ per volume. ${ }^{39}$

It remains to be seen whether the new regional and state processing centers will be able to operate more economically and with greater speed in the 1970's than did their counterparts, the single-district centers, in the 1960's.

\section{Data Processing Systems}

Observers of centralized processing in the late 1960's increasingly began to predict the use of data processing equipment and computers in the processing units of the Seventies. In fact, two fully computerized operations had already been established in the country by 1967. One of these was the Library Processing Center of the Albuquerque City Schools. The unit began operation as early as September, 1963, on an experimental basis. In the first year, procedures were established to process the materials of one small new elementary school using an assortment of IBM equipment. In March, 1964, processing was initiated on the collections of five additional new elementary schools. By the spring of 1966, the center was functioning efficiently enough to add processing for secondary schools. In March, 1968, the original IBM equipment was changed, and thereafter a Honeywell 1200 unit housed in the school system's Data Processing Department was used. By 1969, the processing center was serving a total of 108 libraries. $^{40}$ 
In 1969, the processing procedures of the Albuquerque center were based on the use of two automated files. The first of these, the card order file, contained ordering information which had been coded and key-punched onto computer cards. Recent books, whether they had been requested by librarians or not, were constantly added to the file. The computer record included a control number, the vendor, author, title, publisher, unit cost, reading level, and a purchase or recommendation level. Three purchase levels were used, and any individual title's rating was based on personal inspection of the volume by the center's personnel and the recommendation of published reviews. Twice a year this file was sorted by purchase level and printed out, thus producing buying lists which were distributed to the individual school librarians. ${ }^{41}$

The card order file's primary purpose, however, was to facilitate the ordering of books. When book orders were received from individual librarians at the center, the basic ordering information for each title was retrieved from this file and printed on both the jobber's order forms and on work sheets which were held for later use by the center. When the requested books were received at the center, these work sheets accompanied each individual title through the remainder of the physical processing. ${ }^{42}$

The second major automated file contained complete cataloging data for all titles processed at the center. This file was stored on tape and was used to produce the catalog cards which accompanied each volume processed. When a new title entered the system, original cataloging was done at the center, and after thorough checking for accuracy, the data was added to the tape file for future use. ${ }^{43}$

As the services and complexity of the Albuquerque operation increased during the 1960's, so also did the size of the staff. When the experimental processing began in 1963, there were five employees consisting of one head cataloger, one clerk, one key-punch operator, one machine operator, and one library consultant. By March, 1969, the staff had increased to nineteen; two catalogers, ten clerks, and three key-punch operators having been added in the interim. ${ }^{44}$

Estimates of production costs were not available for the Albuquerque center; however, figures have been released for the similar operation in the Port Huron, Michigan, School District. This center, in a year of admittedly high production, reported that books were processed at a cost of $75 \not \subset$ to $80 \not \varnothing$ per volume. ${ }^{45}$

The computerization of processing procedures seemed a logical development in the 1960's. Much of the processing work involved time-consuming, repetitive, clerical tasks which could be automated with ease. Experimental projects seemed to indicate that the relatively high cost of data processing equipment would not prove prohibitive. Thus, the increasing appearance of regional centers using computer based procedures offered hope that centralized processing would become an even more efficient and effective organizational pattern in the years ahead.

\section{Conclusion}

When central processing units were first established, it was hoped that they would help to cut the rising cost of processing, relieve school personnel who were weak in cataloging from that responsibility, provide for the speedy processing of increased numbers of materials, and free school librarians for service to their patrons. By the end of the decade, many of these hoped-for advantages had been realized.

Although some centers were plagued by continued rising processing costs, many of the better managed centers were able to show substantial savings or at least stable costs in a time of rapid inflation. As predicted, decreases in expenditures occurred because of the reduced need for expensive employees and reference books as well as because of jobber's discounts. 
Virtually all schools, including those whose librarians were adequate catalogers, reported that central processing provided better quality cataloging than had previously been possible. The information was generally more accurate and more complete. $^{46}$

There were mixed feelings about the speed with which central processing units produced the requested materials. Some librarians claimed that books reached their shelves faster with individual school processing, while others praised the central unit's promptness. Nonetheless, all librarians were in agreement that central processing freed them from time-consuming clerical work for the professional service they were trained to give.

In several school districts, the processing centers were able to provide additional services beyond those initially expected. Many centers found that with a little extra effort their master files could also serve as union catalogs. Such records were quite valuable, especially when the center was a regional or state one and, therefore, had holdings data on numerous individual libraries. Computerized systems were able to provide such added benefits as the publication of suggested buying lists.

Despite the many advantages produced, there were unavoidable problems with central processing. In the early days, some centers were established which were too small to produce effective and economical processing. Also, backlogs and delays occurred in many units. These delays often necessitated the unsatisfactory practice of setting fixed order dates or required selection lists. ${ }^{47}$ A third problem was the resistance of school personnel. In some school systems, school administrators were unwilling to recognize the need for centralized processing even when backlogs of uncataloged materials at the individual schools were high. ${ }^{48}$ In other systems, it was the individual school librarians who felt threatened and who resisted. These librarians' usual complaints were that they did not get to examine the books thor- oughly and that subject headings and classification numbers were not sufficiently adapted to the needs of each individual library. ${ }^{49}$

Generally, however, the use of centralized processing in school systems was a success. The predominant attitude held in 1969, after ten years of experience with centralized processing, was well summarized in the 1969 Standards for School Media Programs:

It is advisable to have materials cataloged and processed through some agency outside the school building. This insures skilled service, avoids duplication of effort, and provides maximum time for the professional staff of the school media center to work directly with students and teachers. Moreover, it makes materials immediately accessible upon their delivery to the media center.

Arrangements for centralized processing are practical and recommended for any school system or cluster of cooperative schools. ${ }^{50}$

\section{NOTES}

'Richard L. Darling, "School Library Processing Centers," LIBRARY TRENDS, XVI (July, 1967), 58.

${ }^{2}$ Greensboro, North Carolina, Public Schools, Centralized Ordering, Cataloging, and Processing of Library Materials: An Outline (Greensboro, North Carolina, 1969), p. 1.

3Darling, "School Library Processing Centers," p. 59.

${ }^{4} \mathrm{M}$. Bernice Wiese and Catherine Whitehorn, Centralized Cataloging and Processing in the Baltimore Public Schools: Five Year Report, 1956-61 (Chicago: American Association of School Librarians, 1962), p. 1.

5Darling, "School Library Processing Centers," p. 58.

${ }^{6}$ Wiese, Centralized Cataloging and Processing in the Baltimore Public Schools, p. 2.

${ }^{7}$ Mary Helen Mahar and Doris C. Holladay, Statistics of Public School Libraries, 1960-61, Part 1, quoted in Darling, "School Library Processing Centers," p. 62.

${ }^{8}$ American Association of School Librarians, Standards for School Library Programs (Chicago: American Library Association, 1960), p. 112. 
${ }^{9}$ Richard L. Darling, "Is Centralized Processing for You?" SCHOOL LIBRARY JOURNAL, XIII (December, 1966), 16.

${ }^{10}$ Richard L. Darling, "Streamlining for Service," Appendix $\mathrm{K}$ in The School Library: A Force for Educational Excellence, by Ruth Ann Davies (New York: Bowker, 1969), p. 223.

"Viola James, "Patterns of Administering in Processing of Resources for the School Library Materials Center," in The School Library Materials Center, ed. by Alice Lohrer (Champaign, Illinois: Distributed by the Illini Union Bookstore, 1964), p. 36.

${ }^{12}$ Darling, "Streamlining for Service," p. 224.

13James, "Patterns of Administering the Processing of Resources," p. 42.

${ }^{14}$ Mary Helen Mahar and Doris C. Holladay, Statistics of Public School Libraries, 1960-61, Part I, quoted in Darling, "School Library Processing Centers," p. 62.

${ }^{15}$ Richard L. Darling, "Professional Positions in School Librarianship," LIBRARY TRENDS, XVI (April, 1968), 436, 444.

${ }^{16}$ Darling, "Streamlining for Service," p. 224.

17 James, "Patterns of Administering the Processing of Resources," pp. 43-44.

${ }^{18}$ Gladys M. Lively, "The Creative Elementary School Library and Centralized Processing," WILSON LIBRARY BULLETIN, XXXVI (May, 1962), 753.

19 James, "Patterns of Administering the Processing of Resources," p. 42.

${ }^{20}$ Frances Henne, "Standards for School Library Services at the District Level," LIBRARY TRENDS, XVI (April, 1968), 508.

${ }^{21}$ Darling, "Streamlining for Service," p. 225.

${ }^{22}$ Lively, "The Creative Elementary School Library," p. 756.

${ }^{23}$ Vincent J. Aceto, "Panacea or Pandora's Box? A Look at Central Processing in New York State," SCHOOL LIBRARY JOURNAL, XI (January, 1964), 27.

${ }^{24}$ Ibid., pp. 26-27.

${ }^{25}$ Wiese, Centralized Cataloging and Processing in the Baltimore Public Schools, p. 3.

${ }^{26}$ Ibid., pp. 3-5.

${ }^{27}$ Ibid., pp. 6-8.

${ }^{28}$ Ibid., pp. 5-6.

${ }^{29}$ Ibid., p. 6.

30 lbid., p. 15.

31James, "Patterns of Administering the Processing of Resources," p. 41.

${ }^{32}$ Greensboro, North Carolina, Centralized Ordering, pp. 6, 8, 10, 13.

${ }^{33}$ James, "Patterns of Administering for Processing of Resources," p. 41.

${ }^{34}$ Interview with Mrs. Stella Townsend, Head Cataloger, Library Department Processing Center, Greensboro Public Schools, March 16, 1972.

${ }^{35}$ Ibid.

${ }^{36} \mathrm{Greensboro,} \mathrm{North} \mathrm{Carolina,} \mathrm{Centralized} \mathrm{Order-}$ ing, p. 4.
${ }^{37}$ H. G. Kurtz, "Centralized Processing, Diversified," LIBRARY JOURNAL, XCV (May 15, 1970), 1807. ${ }^{38}$ /bid., pp. 1808-10.

39 /bid., p. 1807.

${ }^{40}$ Mildred Breiland, "Centralized Data Processing for Libraries in the Albuquerque Public Schools, DREXEL LIBRARY QUARTERLY, V (April, 1969), 92-94.

${ }^{41}$ Ibid., p. 94.

${ }^{42}$ Ibid., p. 95.

${ }^{43}$ lbid., pp. 96-98.

${ }^{44}$ Ibid., pp. $92-93$.

${ }^{45}$ Darling, "Is Centralized Processing for You?" p. 16 .

${ }^{46}$ Wiese, Centralized Cataloging and Processing in the Baltimore Public Schools, p. 10.

${ }^{47}$ Darling, "School Library Processing Centers," p. 61 .

${ }^{48}$ Brooke B. Anson, "Central Processing in Illinois School Libraries," ILLINOIS LIBRARIES, LII (November, 1970), 962.

${ }^{49}$ Wiese, Centralized Cataloging and Processing in the Baltimore Public Schools, p. 11.

${ }^{50}$ American Association of School Librarians, Standards for School Media Programs (Chicago: American Library Association, 1969), p. 26.
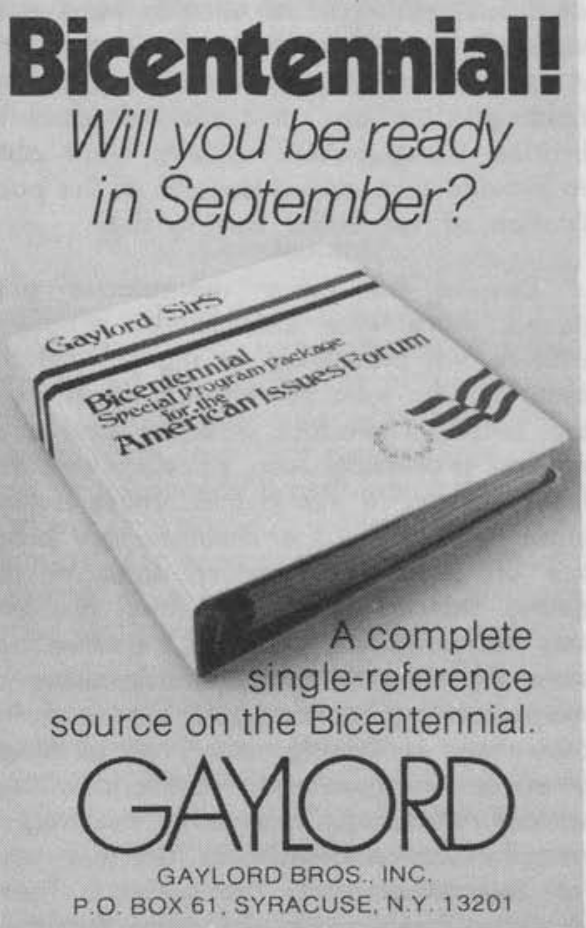